\title{
The Ideological Origins of Great Power Politics,
}

\author{
1789-1989
}

\section{Marc Belissa}

\section{(2) OpenEdition \\ 1 Journals}

\section{Édition électronique}

URL : https://journals.openedition.org/ahrf/8063

DOI : 10.4000/ahrf.8063

ISSN : 1952-403X

Éditeur :

Armand Colin, Société des études robespierristes

\section{Édition imprimée}

Date de publication : 1 décembre 2006

Pagination : 199-200

ISSN : 0003-4436

\section{Référence électronique}

Marc Belissa, «The Ideological Origins of Great Power Politics, 1789-1989 », Annales historiques de la Révolution française [En ligne], 346 | Octobre/Décembre 2006, mis en ligne le 10 juillet 2008, consulté le 24 avril 2022. URL : http://journals.openedition.org/ahrf/8063 ; DOI : https://doi.org/10.4000/ahrf. 8063

Ce document a été généré automatiquement le 24 avril 2022.

Tous droits réservés 


\title{
The Ideological Origins of Great Power Politics, 1789-1989
}

\author{
Marc Belissa
}

\section{RÉFÉRENCE}

Mark L. Hass, The Ideological Origins of Great Power Politics, 1789-1989, Ithaca and London, Cornell University Press, 2005, 232 p., ISBN 0-8014-4321-0, 39.95 \$.

1 L'ouvrage de Mark Haas n'est pas un livre d'histoire, mais de sciences politiques et relève plus précisément de ce que l'on a coutume d'appeler les IR Theories, c'est-à-dire les théories des relations internationales. Il s'agit non d'une étude idéologique ou politique des conceptions des relations internationales depuis deux siècles, mais d'une tentative d'élaboration d'un schéma explicatif général des tensions internationales dont l'ambition est de fournir une ligne de conduite aux dirigeants politiques mondiaux pour éviter les conflits (p. 3). Seul le chapitre 2 traite de la Révolution française. On ne trouve pas dans cet ouvrage de lectures de sources de la période révolutionnaire, l'auteur s'appuie sur une historiographie relativement ancienne avec seulement quelques incursions chez les travaux des historiens britanniques récents, dont ceux de Jennifer Mori. La seule mention de l'historiographie française renvoie à Georges Lefebvre. Les lecteurs des AHRF n'apprendront donc rien de nouveau sur la Révolution française dans ce livre dont l'intérêt est surtout de critiquer les conceptions dites " réalistes » des relations internationales. Rappelons que les IR Theories sont dominées depuis le début $\mathrm{du} \mathrm{XX}^{\mathrm{e}}$ siècle par une approche dite "réaliste " qui assimile les relations internationales à un jeu hobbesien dans lequel les États égoïstes défendent des intérêts matériels relevant de la «nature » géopolitique des choses. Mark Hass s'inscrit contre cette tradition et entend montrer que l'idéologie est un élément déterminant dans la perception par les dirigeants politiques de la nature des menaces internationales. Plus la distance idéologique subjective est grande entre deux groupes de dirigeants, plus la perception de la menace sera grande. À l'inverse, la proximité idéologique des dirigeants implique une perception plus pacifique des rapports 
interétatiques. L'auteur insiste sur le fait que ce n'est pas le contenu idéologique qui détermine la menace, mais l'éloignement des points de vue. Appliquant ces présupposés théoriques à la Révolution française, il affirme que les tensions entre la France et les puissances européennes sont largement dues à l'écart idéologique entre dirigeants français et anglais (les autres puissances sont ignorées) à partir de Varennes et surtout à partir de l'automne 1792. On pourra à bon droit trouver cette vision un peu schématique. À vouloir plaquer des schémas sur l'événement révolutionnaire, l'auteur aboutit à des affirmations étonnantes, par exemple que Louis XVI n'a pas « ardemment " fait pression sur les puissances européennes pour revenir à l'Ancien Régime (p. 43) alors que toute la stratégie de la cour depuis 1789 est au contraire d'obtenir des puissances qu'elles interviennent sous la forme d'un Congrès général, ou que Louis XVI était «à un degré important satisfait des résultats de la Révolution »! La même interprétation amène l'auteur à considérer que, puisque la plupart des monarques européens étaient influencés par les Lumières (mais lesquelles ?), ceux-ci ne considéraient pas la Révolution française comme un danger avant l'été 1791 (p. 44), ce qui, là encore, est une vision réductrice. Enfin, on pourra également regretter des caractérisations comme celle "d'infâmes " accolée aux Comités de Salut public et de Sûreté générale ou celle de « collectiviste » appliquée à la Constitution de l'an I.

2 Les historiens sont toujours - et souvent à juste titre - méfiants à l'égard des généralisations et des schémas interprétatifs quelque peu rigides qui tentent d'expliquer les phénomènes les plus complexes comme les tensions interétatiques. Cet ouvrage n'échappe pas au reproche. C'est à partir de théories qui mériteraient la discussion en elles-mêmes que l'auteur entend décrire les mécanismes qui aboutissent au déclenchement des conflits. Il parle ainsi de «nature humaine ", de "théories de la communication ", de "théories des identités sociales " sans que l'on sache très bien comment ces paradigmes théoriques peuvent s'appliquer aux situations historiques concrètes.

Que l'idéologie des dirigeants (et des individus en général d'ailleurs, oubliés ici) soit un facteur des relations entre les États, personne n'en doute et on pourra trouver que l'auteur enfonce généreusement des portes ouvertes. Encore faudrait-il savoir de quelles idéologies il s'agit et surtout de les contextualiser plus finement, ce qui est difficile quand on survole deux siècles de tensions internationales de la Révolution française à Al Qaida. 